\title{
Outcomes of pregnancy with cardiac diseases in a tertiary care center
}

\author{
Dr.Sasikala MD,OG,DR.Murugalakshmi MD.,DGO.,Dr.E.Indhumathi.DGO. \\ Department of Obstetrics and Gynecology, Coimbatore Medical College Hospital. \\ DOI: 10.29322/IJSRP.10.02.2020.p9811 \\ http://dx.doi.org/10.29322/IJSRP.10.02.2020.p9811
}

\begin{abstract}
To assess the prognosis and outcome of heart disease in pregnancy in order to reduce the maternal mortality due to cardiac disease.
\end{abstract}

Index Terms- Cardiac disease,ECHO,maternal outcome

\section{INTRODUCTION}

$\mathrm{T}$ he steady decline in maternal mortality over the last 20 years has largely been due to a substantial reduction in the number of deaths attributed to hypertensive disorders, hemorrhage, sepsis and abortions. In contrast, the relative contribution of cardiac disease to maternal mortality has remained unchanged and this is still one of the leading causes of adverse maternal outcome worldwide. The frequency of cardiac disease in pregnancy varies from $0.9 \%$ to $3.7 \%$. Contrary to the West, rheumatic heart disease (RHD) still predominates in developing countries such as India, where it constitutes $40-50 \%$ of all cardiac diseases during pregnancy. Among patients with RHD and pregnancy, mitral stenosis (MS) is the most common lesion. ${ }^{1}$

Hemodynamic changes during normal pregnancy are tolerated by women with normal cardiac reserve. Diseased heart shows signs of decompensation with resultant increase in morbidity and mortality. It is natural to expect that the fetus would also be compromised in these mothers. Fetal health depends upon an adequate and continuous supply of well oxygenated maternal blood. In uncompensated heart disease, the oxygen supply becomes limited and that result in compromised fetal growth, there can be growth restriction, premature birth or may even fetal death. ${ }^{2}$ Cardiac disease during pregnancy is a challenge to obstetrician as common clinical features of cardiac lesions like breathlessness; pedal edema and murmur mimic normal pregnancy posing a diagnostic difficulty. In many pregnant women, heart disease still remains undiagnosed until complications develop especially from rural population. Even after the diagnosis, many women do not comply with the instructions given by obstetrician for various reasons. ${ }^{3}$

\section{METHODOLOGY}

The present study was carried out over a period of 12 months (from January 2018 to December 2018) at Department of Obstetrics and Gynaecology, Coimbatore Medical College Hospital. Data was collected from patient clinical records and maternity registers. The patients included both elective and emergency procedures. It is a retrospective analysis. All antenatal women diagnosed to be having heart disease were included in the study. As this was a retrospective audit with no patient intervention or interaction, Institute Ethics Committee approval and informed consent was not taken.

Cases were referred to cardiologists for confirmation of cardiac disease and to seek their opinion regarding management. Cases directly reporting to labour room were also included in the study. Detailed obstetric history was also gathered to know the effect of cardiac disease on pregnancy and vice versa .Thorough clinical examination was done to find out the type of cardiac lesion, any signs of failure and stage of pregnancy. The case was then investigated with specific investigations to confirm the cardiac lesion and the cardiac functional status. Patients were advised to have regular antenatal check-up. They were told about the importance of rest, medication and regular visits. In every visit, patients were referred to physician for their opinion regarding cardiac status.

Patients were counselled regarding the importance of compulsory institutional delivery .Cases reporting during labour were managed as per the cardiac conditions. Postnatally patients were discharged after 14 days with advice about contraception, breast feeding, penicillin prophylaxis, other medications if any and timely review. In case of maternal mortality the cause of death was noted.

\section{Inclusion criteria:}

Pregnant women with a history of or newly diagnosed cardiac disease were included in the study.

\section{Exclusion criteria:}

All conditions mimicking heart disease were excluded.

\section{RESULTS}

A total of 7200 deliveries were conducted during the study period. Out of these 67 cases were found to be associated with cardiac condition. The incidence of cardiac cases associated with pregnancy during the study period was $.93 \%$.

Of the 67 patients, majority of patients were in the age group of 23-27 years (37.0\%) and 27\% belonged to $18-22$ years 
Maternal characteristics, age wise distribution:

\begin{tabular}{|l|l|l|}
\hline AGE IN YEARS & NO OF PATIENTS & PERCENTAGE \\
\hline $18-22$ & 18 & $27 \%$ \\
\hline $23-27$ & 25 & $37 \%$ \\
\hline $28-32$ & 17 & $26 \%$ \\
\hline$>32$ & 7 & $10 \%$ \\
\hline
\end{tabular}

Among the 67 pregnant women $44 \%$ were primigravida, $39 \%$ were second gravida and $17 \%$ were gravida 3 or more.

Parity wise distribution:

\begin{tabular}{|l|l|l|}
\hline GRAVIDA & NO OF PATIENTS & PERCENTAGE \\
\hline PRIMI & 30 & $44 \%$ \\
\hline G2 & 26 & $39 \%$ \\
\hline G3 OR MORE & 11 & $17 \%$ \\
\hline
\end{tabular}

Most of the patient in the study had rheumatic heart disease like MS, MR or AS(67.5\%), followed by TR, PR(29.5\%) and few had sequelae of congenital cardiac condition- Pulmonary Arterial Hypertension $(9 \%)$.

\begin{tabular}{|l|l|l|}
\hline CARDIAC LESIONS & No Of Patients & Percentage \\
\hline Mitral Stenosis & 11 & $17 \%$ \\
\hline Mitral Regurgitation & 33 & $49 \%$ \\
\hline Aortic Stenosis & 1 & $1.50 \%$ \\
\hline Tricuspid Regurgitation & 19 & $28 \%$ \\
\hline Pulmonary Regurgitation & 1 & $1.50 \%$ \\
\hline Pulmonary Artery Hypertension & 6 & $9 \%$ \\
\hline
\end{tabular}

Most of patients had Emergency LSCS (45\%) followed by elective LSCS (24\%). Normal vaginal delivery was conducted only in $19 \%$ of study population.

\begin{tabular}{|l|l|l|l|}
\hline & $\begin{array}{l}\text { TYPE OF } \\
\text { DELIVERY }\end{array}$ & NO OF PATIENTS & PERCENTAGE \\
\hline Labour Naturalis & 13 & $19 \%$ \\
\hline Elective LSCS & 16 & $24 \%$ \\
\hline $\begin{array}{l}\text { Emergency } \\
\text { LSCS }\end{array}$ & 29 & $43 \%$ \\
\hline $\begin{array}{l}\text { Vacuum } \\
\text { Aspiration }\end{array}$ & 1 & $1.50 \%$ \\
\hline Forceps & 2 & $3 \%$ \\
\hline
\end{tabular}

Most of the babies were of normal weight (52\%).

\begin{tabular}{|l|l|l|}
\hline $\begin{array}{l}\text { WEIGH } \\
\text { T OF } \\
\text { BABY }\end{array}$ & $\begin{array}{l}\text { NO } \\
\text { OF } \\
\text { PATIE }\end{array}$ & PERCENTAGE \\
\hline$<2$ KG & 5 & $8 \%$ \\
\hline $\begin{array}{l}2-2.5 \\
\text { KG }\end{array}$ & 25 & $37 \%$ \\
\hline $\begin{array}{l}>\quad 2.5 \\
\text { KG }\end{array}$ & 35 & $52 \%$ \\
\hline
\end{tabular}

Majority of the patients were discharged in good condition $(91 \%)$. There were four maternal deaths during the study period which was complicated by cardiac condition (6\%).I

\begin{tabular}{|l|l|l|}
\hline $\begin{array}{l}\text { MATERNAL } \\
\text { OUTCOME }\end{array}$ & $\begin{array}{l}\text { NO OF } \\
\text { PATIENTS }\end{array}$ & $\begin{array}{l}\text { PERCENTA } \\
\text { GE }\end{array}$ \\
\hline $\begin{array}{l}\text { Discharged In Good } \\
\text { Condition }\end{array}$ & 61 & $91 \%$ \\
\hline Death & 4 & $6 \%$ \\
\hline Referred & 2 & $3 \%$ \\
\hline
\end{tabular}

The various causes for maternal mortality are listed below.

\section{DISCUSSION}

Cardiac disease continues to be a risk factor for maternal and neonatal morbidity and mortality. This study reflects the maternal and fetal outcome in pregnant women with cardiac disease managed at a tertiary care centre in India where cardiac disease due to rheumatic etiology predominates over congenital. In developed countries, the diagnosis and management of cardiac disease starts early.

In this study, $44 \%$ women were diagnosed to have cardiac disease in the index pregnancy. In a recent study by Desai et al. including 128 patients with MS, $42 \%$ of them were diagnosed for the first time during pregnancy ${ }^{5}$. Routine examination of the cardiovascular system in the antenatal clinic is therefore essential for early diagnosis and appropriate management.

Maternal problems during pregnancy in women with cardiac disease include congestive heart failure, arrhythmia, infective endocarditis, respiratory tract infection and the need to either initiate or increase cardioactive drugs or hospitalize these women during pregnancy ${ }^{6}$

An increased incidence of IUGR and low birth weight has been reported in patients with cardiac disease in pregnancy. Postulated reasons for the increased incidence of IUGR or prematurity include hemodynamic compromise secondary to valvular stenosis, maternal arrhythmias and cardioactive drugs including diuretics, digitalis and beta blockers, which have been associated with impairment of uterine blood flow. ${ }^{78910}$

Surgical or catheter-based angiographic correction of cardiac lesions improves pregnancy outcome. The cross-sectional area of the valve can be increased by approximately two-fold by balloon interventions, thus reducing the complications associated with cardiac overload during pregnancy. This explains the better maternal and fetal outcome seen in this study in those pregnant 
women who underwent corrective valve interventions. Restenosis of stenotic valvular lesions has been reported in $27 \%$ of patients [16]. In younger patients with non-calcified, thin valves without subvalvular thickening or significant mitral regurgitation, the rate of restenosis is low. ${ }^{11}$

The mortality rate \& LSCS rate in this study is high. This may be due to the fact that this being a tertiary care centre patients referred here are of very high risk \& most of them referred after a delay. This leads to loss of valuable time leading to irreversible complications. This study highlights the need for timely referral \& provision of adequate facilities in the primary \& secondary centres.

\section{CONCLUSION}

Heart disease complicating pregnancy is a high risk situation and demands special attention throughout pregnancy. An expert supervision and management by the obstetrician along with physician and the fullest co-operation by the patient throughout antenatal, intranatal and post-natal period, results in achieving the optimum maternal and perinatal outcome. It is essential to educate the rural population about the importance of regular antenatal visits and institutional delivery. Establishing the facilitities for cardiac surgery at affordable cost in rural area will certainly go a long way in decreasing the mortality, morbidity related to heart disease complicating pregnancy

\section{REFERENCES}

[1] 1. Bhatla, N. et al. Cardiac disease in pregnancy. Int. J. Gynecol. Obstet. $82,153-159$ (2003).
[2] 2. Sundaram, J. CLINICAL STUDY OF HEART DISEASE COMPLICATING PREGNANCY IN A TERTIARY. at $<$ http://www.journalcra.com>

[3] 3. Pujitha, K. S., Sheela, S. R. \& S, N. J. Original Research Article A study of maternal and fetal outcome in cardiac disease in pregnancy at tertiary care center. 6, 5095-5098 (2017)

[4] 4. Pushpalatha, K. Cardiac Diseases in Pregnancy-A Review . NORMAL PHYSIOLOGIC CHANGES. Jimsa 23, 269-274 (2010).

[5] 5. Desai, D. K., Adanlawo, M., Naidoo, D. P., Moodley, J. \& Kleinschmidt, I. Mitral stenosis in pregnancy: a four-year experience at King Edward VIII Hospital, Durban, South Africa. BJOG 107, 953-8 (2000).

[6] 6. Hameed, A. et al. The effect of valvular heart disease on maternal and fetal outcome of pregnancy. J. Am. Coll. Cardiol. 37, 893-9 (2001).

[7] 7. Al Kasab, S. M. et al. $\beta$-Adrenergic receptor blockade in the management of pregnant women with mitral stenosis. Am. J. Obstet. Gynecol. 163, 37-40 (1990).

[8] 8. American Gynecological Society. American journal of obstetrics and gynecology. (C.V. Mosby Co).

[9] 9. Suri, V., Sawhney, H., Vasishta, K., Renuka, T. \& Grover, A. Pregnancy following cardiac valve replacement surgery. Int. J. Gynaecol. Obstet. 64, 239-46 (1999)

[10] 10. Hanania, G. et al. Pregnancy and prosthetic heart valves: a French cooperative retrospective study of 155 cases. Eur. Heart J. 15, 1651-8 (1994).

[11] 11. Hung, J. S. et al. Short- and long-term results of catheter balloon percutaneous transvenous mitral commissurotomy. Am. J. Cardiol. 67, 854$62(1991)$.

\section{AUTHORS}

First Author - Dr.Sasikala, MDOG,Coimbatore medical college hospital and thanjaikovai@rediff.com.

Second Author - Dr.MurugalakshmiMD.DGO, Coimbatore medical college hospital, and dr.murugalakshmi@gmail.com Third Author - Dr.E.Indhumathi,DGO,Coimbatore Medical College and indhustanlean@gmail.com 